\title{
PARAMETRIC ANALYSIS OF A BIOKINETIC MODEL: A CONTRIBUTION TO THE STUDY OF MODEL RELIABILITY
}

\author{
M. C. Lourenço†, J. L. Lipsztein $† \$$ and C. L. Szwarcwald§ \\ $\dagger$ Instituto de Radioproteção e Dosimetria \\ Av. Salvador Allende, s/n, CEP 22780-160, Rio de Janeiro - RJ, Brazil \\ ¥Instituto de Biologia, Universidade do Estado do Rio de Janeiro \\ Av. 28 de Setembro, 87, CEP 20551-030, Rio de Janeiro - RJ, Brazil \\ §Departamento de Saúde, Fundação Oswaldo Cruz \\ Av. Brasil, 4365, CEP 21045-900, Rio de Janeiro - RJ, Brazil
}

\begin{abstract}
Models for simulating radionuclide distribution in the human body involve assumptions on the biokinetic behaviour of the material. An important problem in biokinetic modelling is the correct assignment of transfer coefficients and biological half-lives to tissue compartments. The purpose of this study is the analysis of the variations of the radionuclide contents in the tissue compartments related to variations in the transfer coefficients from blood to the compartments and to variations in the compartments' biological half-lives. A generalised systemic recycling model, consisting of four tissue compartments and two excretion pathways, was used for the parametric analysis. A continuous intake directly to the blood was chosen for this study. Activities in the compartments were calculated for different times, following random selection of the transfer coefficients and half-lives. A computer code was developed to perform the random selection of parameters. Three different case studies were analysed, where different intervals of variation of half-lives in the four compartments were chosen: (a) the same range of variation was assigned to all compartments, (b) the intervals were chosen so that one compartment had a significantly longer half-life than the others, and (c) one compartment had a significantly shorter half-life than the others. Two cases for the intervals of variation of the transfer coefficients were investigated: (a) the same range for the variation of all transfer coefficients from blood to compartments was assumed, and (b) the interval of the variation of one transfer coefficient was significantly larger than the others. A multiple regression analysis method was applied to analyse the results. In this paper the detailed results of the parametric analysis are presented.
\end{abstract}

\section{INTRODUCTION}

The evaluation of exposure due to internal contamination is carried out using in vitro and in vivo bioassay techniques associated with the interpretation of the results. The interpretation of bioassay results is based on mathematical models that simulate the metabolic behaviour of the radionuclides in the human body, including the kinetic equations which describe the intake, retention, translocation and clearance of the material.

The biokinetic models usually applied in radiation protection are those recommended in the publications of the International Commission on Radiological Protection (ICRP) ${ }^{(1-4)}$. The formulations of the ICRP's biokinetic models have passed through important improvements over the years ${ }^{(5)}$. However, the lack of knowledge about the real metabolic behaviour of the radionuclide represents a factor of uncertainty in estimating the committed dose equivalent. Most of the information available relies on experimental data obtained with laboratory animals and stable element data on humans and a little data on human subjects exposed to radionuclides in experimental, medical or occupational settings or accident situations. An important problem to be solved in biokinetic modelling is the correct assignment of the transfer coefficients from blood to compartments and of the biological half-lives of these compartments.

The purpose of this study is to quantify the reliability of a model's prediction in terms of the radionuclide's activity present in the tissue compartments in relation to variations in the transfer coefficient from blood to the compartments and of the compartment's biological halflives. This objective is achieved through a parametric uncertainty analysis which identifies how much of the compartment activity variation may be attributable to parameter variations.

\section{PROCEDURE}

The parametric analysis was performed considering a generalised systemic recycling model, shown in Figure 1. The following assumptions were made: (a) long radioactive half-life; (b) continuous intake of $1 \mathrm{~Bq}^{-1}$ via plasma; (c) $5 \%$ of the activity in tissue compartment 1 eliminated through faeces; (d) passage from blood to urine through compartment 4; and (e) transfer of radionuclide guided by first order kinetic processes.

The retained activities in each compartment of the model can be calculated, at time t, by solving a system of first order differential equations. A computer code that uses the analytical resolution technique of eigenvalues and eigenvectors ${ }^{(6)}$ and was specially developed to calculate activities deposited in human body compartments after intakes of radionuclides was adopted. Two programs were added to the original code. The first is a program that randomly selects values for the transfer 


\section{C. LOURENÇO, J. L. LIPSZTEIN and C. L. SZWARCWALD}

coefficients and for the biological half-lives, for assigned ranges of variations, and the second is a program which updates the information on the kinetics of the element and permits the performance of a large number of simulations. Files with approximately 1000 values for each parameter were generated ${ }^{(7)}$.

Three different case studies were analysed, where different intervals of variation of half-lives in the four compartments were chosen: $\mathrm{T} 1$ - the same range of variation was assigned to all compartments (20-2000 days); T2 - the compartment 2 had a significant longer half-life (1000-2000 days) than the others (20-500 days); T3 - the compartment 2 had a significantly shorter half-life (20-500 days) than the others (10002000 days).

Two cases for the intervals of variation of the transfer coefficients were investigated: Case $\mathrm{A}$ - all transfer coefficients $\left(a_{1}, a_{2}, a_{3}, a_{4}\right)$ varied in the same random intervals of values; Case $\mathrm{B}$ - one transfer coefficient $\left(a_{2}\right)$ was significantly larger $(0.40-0.95)$ than the others. The activities in each compartment were calculated for different exposure times up to seventy years.

Estimation of the relative contribution of each parameter to the compartment activity variations was based

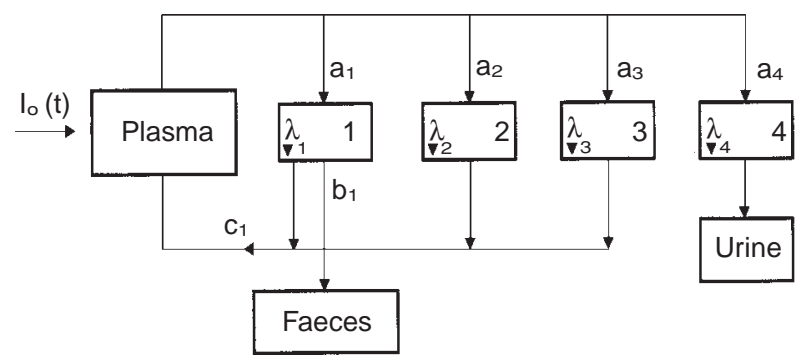

Figure 1. The generalised systemic recycling model $\left(\lambda_{\mathrm{i}}=\ln 2 / \mathrm{t}_{1 / 2}(\mathrm{i})\right)$.

Table 1. The increment in the coefficient of multiple determination to compartment 1 , considering the case study $\mathrm{T} 1$ (20 to 2000 days).

\begin{tabular}{|c|c|c|c|c|c|c|c|c|c|c|}
\hline \multirow{3}{*}{$\begin{array}{l}\text { Time } \\
\text { (y) }\end{array}$} & \multicolumn{8}{|c|}{$\mathrm{R}_{\text {change }}^{2}(\%)$} & \multicolumn{2}{|c|}{$\mathrm{R}^{2}(\%)^{(\mathrm{a})}$} \\
\hline & \multicolumn{2}{|c|}{$a_{1}$} & \multicolumn{2}{|c|}{$\mathrm{t}_{1 / 2}(1)$} & \multicolumn{2}{|c|}{$a_{4}$} & \multicolumn{2}{|c|}{$\mathrm{t}_{1 / 2}(2)$} & \multirow[b]{2}{*}{$\mathrm{A}$} & \multirow[b]{2}{*}{ B } \\
\hline & $\mathrm{A}^{(\mathrm{b})}$ & $\mathrm{B}^{(\mathrm{c})}$ & A & B & A & B & A & B & & \\
\hline 0.5 & 93 & 95 & 2 & 1 & - & - & - & - & 95 & 96 \\
\hline 5 & 66 & 66 & 17 & 10 & 2 & - & - & 6 & 88 & 83 \\
\hline 20 & 49 & 48 & 26 & 19 & 8 & 4 & - & 7 & 84 & 78 \\
\hline 50 & 39 & 51 & 22 & 22 & 13 & 9 & - & 4 & 75 & 73 \\
\hline 70 & 35 & 34 & 20 & 22 & 15 & 10 & - & 3 & 70 & 70 \\
\hline
\end{tabular}

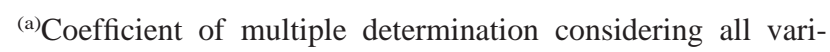
ables selected to regression model.

(b) Case $\mathrm{A}$ of the generalised biokinetic model.

${ }^{(c)}$ Case $\mathrm{B}$ of the generalised biokinetic model. on the statistical technique of multiple linear regression analysis, through the study of the coefficient of multiple determination $\left(\mathrm{R}^{2}\right)^{(8)}$. This coefficient estimates the proportion of the variation of the dependent variable (compartment activity) that is explained by the independent variables (transfer coefficients and biological half-lives). One way to assess this proportion is to consider the increase in $\mathrm{R}^{2}$ when a variable is entered into the regression model previously fitted to the other independent variables. This increase is represented by $\mathrm{R}_{\text {change }}{ }^{2}=\mathrm{R}^{2}-\mathrm{R}_{(\mathrm{i})}{ }^{2}$, where $\mathrm{R}_{(\mathrm{i})}{ }^{2}$ and $\mathrm{R}^{2}$ are, respectively, the multiple determination coefficients when all the independent variables except the $\mathrm{i}^{\mathrm{th}}$ are in the model and when all the independent variables, including the $\mathrm{i}^{\text {th }}$, are in the model. The multiple regression analysis was performed using the statistical computer program 'SPSS for

Table 2. The increment in the coefficient of multiple determination to compartment 1 , considering the case study T2 $\left(t_{1 / 2}(2) \gg t_{1 / 2}(1),(3),(4)\right)$.

\begin{tabular}{|c|c|c|c|c|c|c|c|c|}
\hline \multirow{3}{*}{$\begin{array}{l}\text { Time } \\
\text { (y) }\end{array}$} & \multicolumn{6}{|c|}{$\mathrm{R}_{\text {change }}{ }^{2}(\%)$} & \multicolumn{2}{|c|}{$\mathrm{R}^{2}(\%)^{(\mathrm{a})}$} \\
\hline & \multicolumn{2}{|c|}{$a_{1}$} & \multicolumn{2}{|c|}{$\mathrm{t}_{1 / 2}(1)$} & \multicolumn{2}{|c|}{$\mathrm{a}_{4}$} & & \\
\hline & $\mathrm{A}^{(\mathrm{b})}$ & $\mathrm{B}^{(\mathrm{c})}$ & A & B & A & B & A & B \\
\hline 0.5 & 87 & 91 & 7 & 4 & - & - & 95 & 96 \\
\hline 5 & 57 & 64 & 25 & 19 & - & - & 86 & 85 \\
\hline 20 & 43 & 55 & 22 & 21 & 9 & 2 & 74 & 80 \\
\hline 50 & 33 & 46 & 16 & 21 & 13 & 6 & 62 & 75 \\
\hline 70 & 29 & 41 & 15 & 20 & 14 & 9 & 58 & 73 \\
\hline
\end{tabular}

(a) Coefficient of multiple determination considering all variables selected to regression model.

${ }^{\text {(b) }}$ Case $\mathrm{A}$ of the generalised biokinetic model.

${ }^{(\mathrm{c})}$ Case $\mathrm{B}$ of the generalised biokinetic model.

Table 3. The increment in the coefficient of multiple determination to compartment 1 , considering the case study $\mathrm{T} 3$ $\left(t_{1 / 2}(2) \ll t_{1 / 2}(1),(3),(4)\right)$.

\begin{tabular}{|c|c|c|c|c|c|c|c|c|c|c|}
\hline \multirow{3}{*}{$\begin{array}{l}\text { Time } \\
(\mathrm{y})\end{array}$} & \multicolumn{8}{|c|}{$\mathrm{R}_{\text {change }}{ }^{2}(\%)$} & \multicolumn{2}{|c|}{$\mathrm{R}^{2}(\%)^{(\mathrm{a})}$} \\
\hline & \multicolumn{2}{|c|}{$a_{1}$} & \multicolumn{2}{|c|}{$\mathrm{t}_{1 / 2}(1)$} & \multicolumn{2}{|c|}{$a_{4}$} & \multicolumn{2}{|c|}{$\mathrm{t}_{1 / 2}(2)$} & \multirow[b]{2}{*}{ A } & \multirow[b]{2}{*}{ B } \\
\hline & $\mathrm{A}^{(\mathrm{b})}$ & $\mathrm{B}^{(\mathrm{c})}$ & A & B & A & B & A & B & & \\
\hline 0.5 & 98 & 95 & - & - & - & - & 1 & 2 & 99 & 97 \\
\hline 5 & 91 & 81 & 1 & - & - & - & 1 & 7 & 97 & 92 \\
\hline 20 & 76 & 68 & 2 & 2 & 13 & 13 & - & 4 & 93 & 88 \\
\hline 50 & 58 & 51 & 3 & 3 & 22 & 24 & - & - & 83 & 79 \\
\hline 70 & 52 & 43 & 3 & 4 & 23 & 27 & - & - & 78 & 75 \\
\hline
\end{tabular}

${ }^{(a)}$ Coefficient of multiple determination considering all variables selected to regression model.

${ }^{(b)}$ Case $\mathrm{A}$ of the generalised biokinetic model.

${ }^{(c)}$ Case $\mathrm{B}$ of the generalised biokinetic model. 
Windows', release 6.0. A stepwise method was chosen, considering the confidence levels of 0.01 and 0.05 for the entry and removal of independent variables, respectively.

\section{RESULTS AND DISCUSSION}

Increases in the multiple determination coefficient $\left(\mathrm{R}^{2}\right)$ are shown in Tables 1 to 9 for compartments 1,2 and 4 of the generalised model, considering the different intervals of variation of biological half-lives and transfer coefficients. The transfer coefficients from blood to compartments 1,2 and 4 are represented by $\mathrm{a}_{1}, \mathrm{a}_{2}$ and $\mathrm{a}_{4}$, respectively, while the biological half-lives are represented by $t_{1 / 2}(1), t_{1 / 2}(2)$ and $t_{1 / 2}(4)$, respectively. The results obtained for compartments 1 and 3 were similar,

Table 4. The increment in the coefficient of multiple determination to compartment 2 , considering the case study $\mathrm{T} 1$ (20 to 2000 days).

\begin{tabular}{|c|c|c|c|c|c|c|c|c|}
\hline \multirow{3}{*}{$\begin{array}{l}\text { Time } \\
\text { (y) }\end{array}$} & \multicolumn{6}{|c|}{$\mathrm{R}_{\text {change }}{ }^{2}(\%)$} & \multicolumn{2}{|c|}{$\mathrm{R}^{2}(\%)^{(\mathrm{a})}$} \\
\hline & \multicolumn{2}{|c|}{$a_{2}$} & \multicolumn{2}{|c|}{$\mathrm{t}_{1 / 2}(2)$} & \multicolumn{2}{|c|}{$a_{4}$} & \multirow[b]{2}{*}{ A } & \multirow[b]{2}{*}{ B } \\
\hline & $\mathrm{A}^{(\mathrm{b})}$ & $\mathrm{B}^{(\mathrm{c})}$ & A & B & A & B & & \\
\hline 0.5 & 94 & 95 & 2 & 1 & - & - & 96 & 97 \\
\hline 5 & 66 & 67 & 17 & 18 & 2 & - & 88 & 88 \\
\hline 20 & 48 & 54 & 26 & 29 & 8 & 5 & 83 & 89 \\
\hline 50 & 37 & 50 & 22 & 29 & 14 & 7 & 74 & 86 \\
\hline 70 & 33 & 48 & 20 & 27 & 16 & 8 & 69 & 83 \\
\hline
\end{tabular}

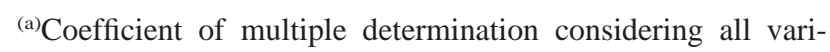
ables selected to regression model.

${ }^{(b)}$ Case $\mathrm{A}$ of the generalised biokinetic model.

${ }^{(\mathrm{c})}$ Case $\mathrm{B}$ of the generalised biokinetic model.

Table 5. The increment in the coefficient of multiple determination to compartment 2 , considering the case study $\mathrm{T} 2$ $\left(t_{1 / 2}(2) \gg t_{1 / 2}(1),(3),(4)\right)$.

\begin{tabular}{|c|c|c|c|c|c|c|c|c|}
\hline \multirow{3}{*}{$\begin{array}{l}\text { Time } \\
\text { (y) }\end{array}$} & \multicolumn{6}{|c|}{$\mathrm{R}_{\text {change }}{ }^{2}(\%)$} & \multicolumn{2}{|c|}{$\mathrm{R}^{2}(\%)^{(\mathrm{a})}$} \\
\hline & \multicolumn{2}{|c|}{$a_{2}$} & \multicolumn{2}{|c|}{$\mathrm{t}_{1 / 2}(2)$} & \multicolumn{2}{|c|}{$a_{4}$} & \multirow[b]{2}{*}{ A } & \multirow[b]{2}{*}{ B } \\
\hline & $\mathrm{A}^{(\mathrm{b})}$ & $\mathrm{B}^{(\mathrm{c})}$ & A & B & A & $\mathrm{B}$ & & \\
\hline 0.5 & 97 & 97 & - & - & - & - & 98 & 99 \\
\hline 5 & 83 & 85 & - & - & 9 & 11 & 95 & 98 \\
\hline 20 & 64 & 74 & 3 & 2 & 22 & 22 & 89 & 97 \\
\hline 50 & 49 & 69 & 3 & 2 & 26 & 22 & 77 & 93 \\
\hline 70 & 43 & 67 & 3 & 2 & 25 & 21 & 72 & 90 \\
\hline
\end{tabular}


ables selected to regression model.

${ }^{(b)}$ Case $\mathrm{A}$ of the generalised biokinetic model.

${ }^{(c)}$ Case $\mathrm{B}$ of the generalised biokinetic model. except for the small quantity of the activity present in compartment 1 which is eliminated through faeces.

For each compartment, a significant proportion of the total variation in its activity may be explained by the transfer coefficient from blood to the compartment. This influence decreases with time as the half-life and the transfer coefficient from blood to compartment 4 are selected into the regression model. The transfer coefficient from blood to the compartment 4 is justified since this compartment does not participate in the recirculation process, and thus the fraction of the activity transferred to this compartment is eliminated through urine with no feedback to the system.

It can be seen (Tables 3 and 5) that when the biological half-lives, in the compartments that participate in the recirculation process, are restricted to high values their

Table 6. The increment in the coefficient of multiple determination to compartment 2 , considering the case study T3 $\left(\mathbf{t}_{1 / 2}(2) \ll \mathbf{t}_{1 / 2}(1),(3),(4)\right)$.

\begin{tabular}{|c|c|c|c|c|c|c|c|c|}
\hline \multirow{3}{*}{$\begin{array}{l}\text { Time } \\
\text { (y) }\end{array}$} & \multicolumn{6}{|c|}{$\mathrm{R}_{\text {change }} 2(\%)$} & \multicolumn{2}{|c|}{$\mathrm{R}^{2}(\%)^{(\mathrm{a})}$} \\
\hline & \multicolumn{2}{|c|}{$\mathrm{a}_{2}$} & \multicolumn{2}{|c|}{$t_{1 / 2}(2)$} & \multicolumn{2}{|c|}{$\mathrm{a}_{4}$} & \multirow[b]{2}{*}{ A } & \multirow[b]{2}{*}{ B } \\
\hline & $\mathrm{A}^{(\mathrm{b})}$ & $\mathrm{B}^{(\mathrm{c})}$ & A & $\mathrm{B}$ & A & $\mathrm{B}$ & & \\
\hline 0.5 & 89 & 91 & 6 & 5 & - & - & 95 & 97 \\
\hline 5 & 60 & 68 & 26 & 23 & - & - & 87 & 91 \\
\hline 20 & 49 & 59 & 24 & 23 & 6 & 1 & 79 & 83 \\
\hline 50 & 38 & 49 & 19 & 19 & 12 & 3 & 69 & 72 \\
\hline 70 & 34 & 45 & 17 & 18 & 14 & 4 & 65 & 67 \\
\hline
\end{tabular}

(a) Coefficient of multiple determination considering all variables selected to regression model.



${ }^{(c)}$ Case $\mathrm{B}$ of the generalised biokinetic model.

Table 7. The increment in the coefficient of multiple determination to compartment 4 , considering the case study $T 1$ (20 to 2000 days).

\begin{tabular}{|c|c|c|c|c|c|c|c|c|}
\hline \multirow{3}{*}{$\begin{array}{l}\text { Time } \\
\text { (y) }\end{array}$} & \multicolumn{6}{|c|}{$\mathrm{R}_{\text {change }}{ }^{2}(\%)$} & \multicolumn{2}{|c|}{$\mathrm{R}^{2}(\%)^{(\mathrm{a})}$} \\
\hline & \multicolumn{2}{|c|}{$a_{4}$} & \multicolumn{2}{|c|}{$t_{1 / 2}(4)$} & \multicolumn{2}{|c|}{$t_{1 / 2}(2)$} & \multirow[b]{2}{*}{ A } & \multirow[b]{2}{*}{ B } \\
\hline & $\mathrm{A}^{(\mathrm{b})}$ & $\mathrm{B}^{(\mathrm{c})}$ & A & B & A & B & & \\
\hline 0.5 & 91 & 94 & 2 & 1 & - & - & 94 & 96 \\
\hline 5 & 48 & 61 & 31 & 14 & - & 7 & 83 & 82 \\
\hline 20 & 23 & 36 & 61 & 33 & - & 8 & 86 & 78 \\
\hline 50 & 10 & 22 & 78 & 51 & - & 5 & 89 & 79 \\
\hline 70 & 7 & 17 & 83 & 58 & - & 4 & 90 & 79 \\
\hline
\end{tabular}

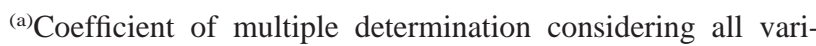
ables selected to regression model.

(b) Case $\mathrm{A}$ of the generalised biokinetic model.

${ }^{(\mathrm{c})}$ Case $\mathrm{B}$ of the generalised biokinetic model. 
Table 8. The increment in the coefficient of multiple determination to compartment 4 , considering the case study $T 2$ $\left(t_{1 / 2}(2) \gg t_{1 / 2}(1),(3),(4)\right)$.

\begin{tabular}{|c|c|c|c|c|c|c|}
\hline \multirow[t]{3}{*}{ Time (y) } & \multicolumn{4}{|c|}{$\mathrm{R}_{\text {change }}{ }^{2}(\%)$} & \multicolumn{2}{|c|}{$\mathrm{R}^{2}(\%)^{(\mathrm{a})}$} \\
\hline & \multicolumn{2}{|c|}{$a_{4}$} & \multicolumn{2}{|c|}{$\mathrm{t}_{1 / 2}(4)$} & \multirow[b]{2}{*}{ A } & \multirow[b]{2}{*}{ B } \\
\hline & $\mathrm{A}^{(\mathrm{b})}$ & $\mathrm{B}^{(\mathrm{c})}$ & A & B & & \\
\hline 0.5 & 79 & 90 & 11 & 5 & 91 & 95 \\
\hline 5 & 34 & 60 & 49 & 24 & 87 & 85 \\
\hline 20 & 16 & 46 & 71 & 34 & 88 & 83 \\
\hline 50 & 7 & 32 & 82 & 47 & 90 & 81 \\
\hline 70 & 6 & 26 & 86 & 53 & 91 & 80 \\
\hline
\end{tabular}

${ }^{(a)}$ Coefficient of multiple determination considering all variables selected to regression model.

(b) Case A of the generalised biokinetic model.

${ }^{(\mathrm{c})}$ Case $\mathrm{B}$ of the generalised biokinetic model.

Table 9. The increment in the coefficient of multiple determination to compartment 4 , considering the case study $\mathrm{T} 3$ $\left(t_{1 / 2}(2) \ll t_{1 / 2}(1),(3),(4)\right)$.

\begin{tabular}{|c|c|c|c|c|c|c|c|c|}
\hline \multirow{3}{*}{$\begin{array}{l}\text { Time } \\
\text { (y) }\end{array}$} & \multicolumn{6}{|c|}{$\mathrm{R}_{\text {change }} 2(\%)$} & \multicolumn{2}{|c|}{$\mathrm{R}^{2}(\%)^{(\mathrm{a})}$} \\
\hline & \multicolumn{2}{|c|}{$\mathrm{a}_{4}$} & \multicolumn{2}{|c|}{$t_{1 / 2}(4)$} & \multicolumn{2}{|c|}{$\mathrm{t}_{1 / 2}(2)$} & \multirow[b]{2}{*}{ A } & \multirow[b]{2}{*}{ B } \\
\hline & $\mathrm{A}^{(\mathrm{b})}$ & $\mathrm{B}^{(\mathrm{c})}$ & A & $\mathrm{B}$ & A & B & & \\
\hline 0.5 & 98 & 95 & - & - & 1 & 2 & 99 & 97 \\
\hline 5 & 89 & 81 & 2 & - & 1 & 8 & 97 & 91 \\
\hline 20 & 68 & 62 & 15 & 8 & - & 5 & 89 & 80 \\
\hline 50 & 41 & 38 & 34 & 22 & - & 3 & 77 & 68 \\
\hline 70 & 33 & 29 & 39 & 29 & - & 2 & 74 & 64 \\
\hline
\end{tabular}

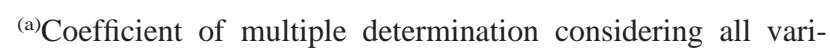
ables selected to regression model.

${ }^{(b)}$ Case $\mathrm{A}$ of the generalised biokinetic model.

${ }^{(c)}$ Case $\mathrm{B}$ of the generalised biokinetic model. influence in the variation of the compartments' activities are smaller.

The variations of the activities of compartments 1 and 4 (Tables 2, 3, 8, 9) due to variations of the parameter $\mathrm{t}_{1 / 2}(2)$ may be explained in Case B by the fact that compartment 2 receives a higher fraction of the activity. A small contribution of the parameter $t_{1 / 2}(2)$ is also observed when a short half-life is attributed to compartment 2 , reflecting a fast feedback to the system. The relative dispersion on the activities of each compartment of the model, due to the variation of the parameters, were determined by the coefficient of variation $(\mathrm{CV})$ of the mean activity in the compartment. Table 10 presents the range of values of the coefficients of variation obtained over 70 years of exposure.

\section{CONCLUSIONS}

For the compartments which participate in the recirculation process the transfer coefficient from blood to the compartment under study is the most important variable in terms of influence on the variation of the activity in the compartment. In the first year of exposure more than $80 \%$ of the variation in the compartments' activity is explained by the variation of this variable. The biological half-life and the transfer coefficient from blood to the compartment which does not participate in the recirculation process have some influence on the variation of the activity of the compartment under study. The maximum value of the coefficients of variation for the mean activities of the compartments is $140 \%$. When one of the compartments receives a higher fraction of the activity present in blood, the range of values for these coefficients of variation decrease for all compartments. For each compartment, this range of values is significantly reduced when the biological half-lives of the compartment are restricted to high values.

For the compartment that does not participate in the recirculation process, the transfer coefficient from blood to the compartment and the biological half-life are the only variables that explain the total variation in the activity of the compartment. In the first years of exposure the transfer coefficient is the most important

Table 10. Coefficients of variation of mean activities in compartments 1,2 and 4 of the generalised biokinetic model through 70 years.

\begin{tabular}{|c|c|c|c|c|c|c|}
\hline \multirow[t]{3}{*}{ Compartment } & \multicolumn{6}{|c|}{ Coefficient of variation (\%) } \\
\hline & \multicolumn{2}{|c|}{$\mathrm{T} 1$} & \multicolumn{2}{|c|}{$\mathrm{T} 2$} & \multicolumn{2}{|c|}{ T3 } \\
\hline & Case A & Case B & Case A & Case B & Case A & Case B \\
\hline 1 & $60-120$ & $80-115$ & $60-140$ & $85-120$ & $55-90$ & $70-90$ \\
\hline 2 & $60-120$ & $25-70$ & $55-105$ & $20-50$ & $65-130$ & $30-110$ \\
\hline 4 & $55-65$ & $75-90$ & $55-65$ & $70-95$ & $30-50$ & $35-80$ \\
\hline
\end{tabular}




\section{PARAMETRIC ANALYSIS OF A BIOKINETIC MODEL}

parameter. As the exposure time increases, the biological half-life becomes the most important variable. The coefficient of variation for the mean compartment activity shows a maximum value of $95 \%$. The values for this coefficient increase when one of the other compartments of the model receives a higher fraction of the activity present in blood and are significantly reduced when the range of biological half-lives assigned to the compartment are restricted to high values.

\section{ACKNOWLEDGEMENT}

This work is part of the $\mathrm{PhD}$ dissertation presented at the Instituto de Biofísica Carlos Chagas Filho, Universidade Federal do Rio de Janeiro, Brazil.

\section{REFERENCES}

1. International Commission on Radiological Protection. Limits for Intakes of Radionuclides by Workers. Part 1. ICRP Publication 30 Ann. ICRP 2(3/4) (Oxford: Pergamon Press) (1979).

2. International Commission on Radiological Protection. Age-Dependent Doses to Members of the Public from Intake of Radionuclides, Part 1. ICRP Publication 56 Ann. ICRP 20(2) (Oxford: Pergamon Press) (1989).

3. International Commission on Radiological Protection. Age-Dependent Doses to Members of the Public from Intake of Radionuclides, Part 2, Ingestion Dose Coefficients. ICRP Publication 67 Ann. ICRP 23(3/4) (Oxford: Elsevier) (1993).

4. International Commission on Radiological Protection, Age-Dependent Doses to Members of the Public from Intake of Radionuclides, Part 3, Ingestion Dose Coefficients. ICRP Publication 69 (Oxford: Elsevier) (1994).

5. Leggett, R. W. and Eckerman, K. F. Evolution of the ICRP's Biokinetic Models. Radiat. Prot. Dosim. 53(1-4), 147-155 (1994).

6. Bertelli, L., Lourenço, M. C., Oliveira, C. A. N. and Lipsztein, J. L. An Analytical Mathematical Method to Calculate Activity in Body Organs and Excreta. In: Proc. Application of Computer Technology to Radiation Protection, IAEA-SR-136/52, Yugoslavia (1989).

7. Lourenço, M. C. Análise Paramétrica de Modelos Biocinéticos Utilizados em Dosimetria Interna. PhD Thesis, Federal University of Rio de Janeiro, Brasil (1997).

8. Draper, N. and Smith, H. Applied Regression Analysis, 2nd edn (New York: John Wiley) (1981) 